\title{
FROM EXCAVATIONS TO WEB: A GIS FOR ARCHAEOLOGY
}

\author{
Maria Grazia D'Urso ${ }^{\mathrm{a}, *}$, Ester Corsi ${ }^{\mathrm{a},{ }^{* *}}$, Sorin Nemeti $^{\mathrm{b}}$, Marco Germani $^{\mathrm{c}}$ \\ ${ }^{\text {a }}$ DICeM, Department of Civil and Mechanical Engineering, University of Cassino and Southern Lazio, \\ Via G. Di Biasio, 4303043 Cassino (Frosinone), Italy \\ *durso@unicas.it,** ester.corsi@gmail.com \\ ${ }^{\mathrm{b}}$ Departamentul de Istorie Antică şi Arheologie, Universitatea Babes-Bolyai, Cluj -Napoca, Str. Mihail Kogalniceanu,1 \\ 400084 Romania, sorinnemeti@yahoo.com
}

${ }^{c}$ Director Museum Khaled Asaad Aquino (Frosinone), Italy, University of Rome Tor Vergata, grmmrc01@uniroma2.it

\section{Commission V, WG V/2}

KEY WORDS: excavation, GIS intra-site, archaeological dig, photogrammetric reconstruction, stratigraphical unit, documentation

\begin{abstract}
The study and the protection of Cultural Heritage in recent years have undergone a revolution about the search tools and the reference disciplines. The technological approach to the problem of the collection, organization and publication of archaeological data using GIS software has completely changed the essence of the traditional methods of investigation, paving the way to the development of several application areas, up to the Cultural Resource Management. A relatively recent specific sector of development for archaeological GIS development sector is dedicated to the intra - site analyses aimed to recording, processing and display information obtained during the excavations. The case - study of the archaeological site located in the south - east of San Pietro Vetere plateau in Aquino, in the Southern Lazio, is concerned with the illustration of a procedure describing the complete digital workflow relative to an intra-site analysis of an archaeological dig. The GIS project implementation and its publication on the web, thanks to several softwares, particularly the FOSS (Free Open Source Software) Quantum - GIS, are an opportunity to reflect on the strengths and the critical nature of this particular application of the GIS technology. For future developments in research it is of fundamental importance the identification of a digital protocol for processing of excavations (from the acquisition, cataloguing, up data insertion), also on account of a possible future Open Project on medieval Aquino.
\end{abstract}

\section{INTRODUCTION}

Currently the spreading of information about Cultural Heritage, through the new digital information technologies represents the conclusive phase of documentation and digital classification of Heritage, particularly of the archaeological sites with reference to all historical, geometric and semantic aspects. Nowadays the virtual documentation challenges with the progress of informatics and its multi-medial spatial computer systems, in which the 2D and 3D modeling can be further used for the digital reconstructions (Bitelli et alii, 2004).

In this context Geomatics, with the help of GIS, allows us a cultural investigation of the territory, introducing an innovative cognitive perspective that overcomes the typically spatial aspect, "materializing" the memory of the excavations context.

In particular the dynamic aspect of the information embedded in GIS, since it can be continuously modified and updated, is one of the reasons for which this instrument is appointively considered towards the research not only in archaeology.

It is important to underline that the realization of a GIS project in the archaeological field requires the contribute and collaboration of several professionalisms (archaeologists, engineers, surveyors, computer engineers, historians, geologists), to get a correct rationalization and data interpretation.
Actually if it is true that a GIS software is able to store and manage several information combined by spatial identification, is true as well that to be really productive, a GIS platform must be inserted in a network that, besides the software and hardware components, collects database,

people, organizations and institutional agreements according to focused rationales.

Granted for this we present the first results of archaeological digs begun and self-financed in 2015, by a team of people working at the University of Cassino and Southern Lazio in collaboration with archaeologists of the Romanian University of Babes-Bolyai in Cluj-Napoca and of the public Museum Khaled Asaad in Aquino (FR). Our aim was to investigate the ruins of S. Maria degli Angeli Church, dated to the highmedieval age and sited within the municipality of Aquino. Preliminarily, objective of the excavations has been to check, as many as elements and archaeological evidences, related both to the structure of the old building of the Church and of the Lombard area as a whole, and how they have evolved from the end of VI century A.C.

These first results have allowed us to deduce further elements from the interpretation of the findings useful not only to study the historical evolution of Aquinum, beginning from the late antiquity to the dark age, on which contrasting theories still hold, but also to consider guidelines and a digital protocol to elaborate the data of archaeological digs

\footnotetext{
* Corresponding author
} 
applicable also to analogous topographic, historical and cultural contexts.

\section{GIS and ARCHAEOLOGY}

In the analysis of the Cultural Heritage, particularly in the archaeological one, localization and spatial dimension of sites represent predominant features. GIS applications allow one to spread geo-spatial data in the web by exploiting the analyses carried out by software that process geographical data and disseminate geographical information in internet based on basic client-server features as in a classical web architecture. Currently it is possible to list some applicative fields of GIS tools within the archaeological research:

1) Survey (Analysis of sites of interest for forecasting the archaeological potential); 2) Landscape Archaeology (Spatial analysis and modeling based upon the correlation existing between population, environment and culture of a given territory); 3) Intra-site GIS, i.e. GIS systems for excavations (digitalization of drawings, maps, plans, images, 2D and 3D reconstructions, Virtual Reality); 4) Cultural Resource Management (Management of Cultural Heritage for its protection, safety and promotion).

Intra-site spatial analyses represent a specific and almost recent sector of development for GIS applications and in Italy such experimental applications to excavations dates back to the second half of nineties. Differently from the traditional application fields in archaeology, the "intra-site" GIS requires a deeper methodological and critical path. Actually a particular attention is required for recovering and digital conversion of multi-temporal and multi-scale data obtained by several techniques concerning different geographical projections and topographical precision relevant to the area under examination, the choice of an effective way of stratigraphical representation, in order to highlight the spatial distribution of the findings and strata sequence in a restricted geographical scale, and, finally, the adoption of traditional functions of GIS spatial analysis, designed and implemented at a regional scale, to the needs of investigating small geographical sites.

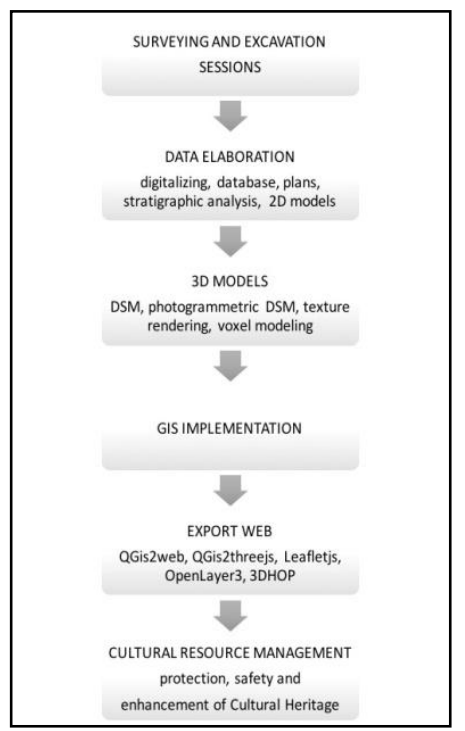

Figure 1. Flowchart of a GIS intra-site

As schematically represented in the above flow-chart, these aspects require some guidelines in the preliminary stage of a GIS design. Hence, from the elaboration of three-dimensional models through the stratigraphical sequence of level, to the production of interactive maps of the excavation sections, the principal aim of the GIS application concerning the case study is to set up a tool for sharing archives and the visualization of the findings from the very beginning to the end of the archaeological survey.

\section{HISTORICAL GEOGRAPHIC FRAMEWORK}

\subsection{Topography and evolution of urban center of Aquino: annotations about archaeological evidences}

The Liri Valley territory, in particular the level land located at the south of Mount Cairo and extending just before the Aquino Deep Valley, also called Pentine Deep Valley, exhibits archaeological findings of human settlements dating back to the prehistoric age. More specifically they cover an historical period ranging from the Inferior Paleolithic to the Bronze and Iron age, up the millenia and centuries before the occupation of the area by the Volsci (VII-VI century B.C.).

During the roman age the city attains its utmost expansion, mainly within the late republican age and the first imperial one. Starting from the late roman age the city of Aquinum has been charachterized by an increase of rural habits that has become progressively more evident during our days from roman to lombard, to medieval city up to transforming in a modern city.

The area of the Aquino Deep Valley, placed at the east of the roman and late-antique residential area, was originally occupied by three small lakes supplied by the springs of Capo d'Acqua (Castrocielo, FR) for which, still today, it is possible to identify in aerial images Le Sogne or Le Forme (Piro et alii, 2011).

Probably the denomination Aquinum comes from the wealth of springs of freshwater in the surroundings and its area extended to the west of the lakes in the plane of San Pietro Vetere along the layout of the Latina road, an important arterial road between Lazio and Campania.

To witness the growing importance of the new town and of its commercial role in the valley, some important authors (Cicerone, Phil 2, 106) define the town as frequens municipium.

The strategic importance of the town is also witnessed, besides the citation in Strabone (V, 3, 9), by its inclusion in the Itinerarium Antoninum (302, 3-5) and in the Tabula Peutingeriana.

Hence, the presence of such historical sources is particularly relevant for reconstructing not only the practicability in the Liris valley but also to understand the strategic and commercial role played by the town during the republican and imperial age (Ceraudo, 2012; Nicosia, Ceraudo, 2007). Starting from the late imperial age a progressive phase of depopulation and dispersion has produced significant changes in the dislocation of the inhabited area. Although a built-up area seems to be still active, on the west of lakes, in the south-east zone of the old roman town, till the destruction made by Corrado IV in 1252, a new residential area begins to grow on the eastside, starting from the $\mathrm{X}$ century, around the castle of the Aquino Counts.

The Lombard domination marks a long period of turmoils of the political and geographical order in the Southern Lazio, producing the passage from the late imperial age to the high medieval one (Nicosia, 1990).

The erection around the castellum praetorium (Chronicon Monasterii Casinensis, II, 2, pag. 168; II, 24, pag. 209) of a fortified village on a rocky spur on the west side of lakes, 
represents the first step toward the final urban layout of the medieval town, first, and of the modern one, at the end.

Findings of a certain value, belonging to the medieval age, found in the urban area destroyed in 1252 include those of the Santa Maria degli Angeli Church and, probably, those of the San Lorenzo Gate whose dating is still argument of a heated discussion (Pietrobono, 2008).

The archaeological digs campaign carried out in 2015 aimed to understand the urban politics adopted in this part of the old inhabited center with particular reference to the remains of the still visible ruins of the Santa Maria degli Angeli Church. The results of the started investigations allow the present study to be framed within the review of the researches relevant to the urban process of the old Aquinum and to the vexata questio concerning the western borders of the inhabited center. Data collected till now, in addition to the other ones collected in the excavation campaigns carried out in previous years, allow us to set up an archive representing the database at the heart of the informative system that we are going to implement.

It is supposed that the area where the Santa Maria degli Angeli Church has been erected represents the site in which the Lombards settled at their arrival in 587-589 and that they hold under their power till 859-860 (Fig. 2).

It could stand just before the walls of the roman town already identified on the west side of the ruins under examination and the eastern border of the medieval town.

On the north-west side of the site occupied by the Church it can be identified San Lorenzo Gate and, always along the ancient Latina road but more on the west bound, the Roman Gate.

Outside the two main urban gateways recent studies have ascertained the existence of two large burial areas, particularly outside the San Lorenzo Gate, in the area where Madonna della Libera Church has been erected, and outside Romana Gate in the rest area Casilina Est (A. Di Folco, La necropoli presso la chiesa della Madonna della Libera: le epigrafi, in G. Ceraudo, A. Nicosia 2007, pp. 153-156; Florissi Germani 2015, pp. 21-40; G. R. Bellini, S. L. Trigona 2011, pp. 185-192).

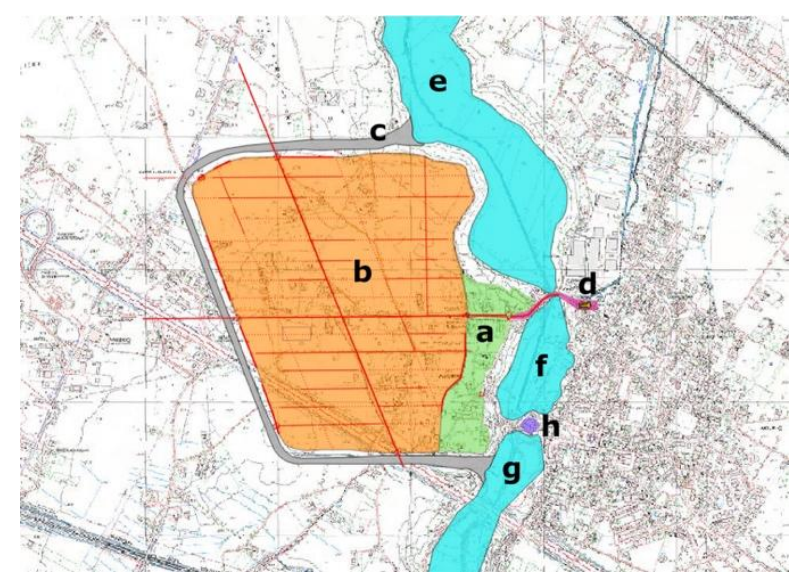

Figure 2. Historical-territorial overview in a GIS: basemap CTR Lazio Region 1:5000; clearly visible the elements concerning the old Aquinum: (a) Lombard area, (b) Roman Ager, (c) old moat, (d) Santa Maria della Libera necropolis, $(\mathrm{e}, \mathrm{f}, \mathrm{g})$ ancient lakes, (h) modern medieval area.

\section{ARCHAEOLOGICAL DIGS IN THE ANTIQUA AQUINUM}

The area in which the digs have been carried out is placed on the San Pietro Vetere plateau; it was considered as a suburban area thanks to the finding of a wall piece, on the south side of San Lorenzo Gate, that was assumed as the eastern border of the roman town. The archaeological dig has been carried out in the proximity of the ruins of the Santa Maria degli Angeli Church. The remains of the Church consist in a single wall belonging to the perimetral border of the building. Currently it is covered by overrunning weeds for the whole height (about 7 meters from the base). Masonry has a baseline at the bottom, probably realized with end products of the roman period, and a raised part realized with unfinished stones set in place with mortar. Two small digs have been excavated in the site and two stratigraphical units (SU) have been detected in each of them. Surveys have been carried out with high precision topographic instruments: a total station, characterized by accuracy of $2 \mathrm{~mm}$ in measuring distances and 0,3 milligon for angular measures, and two geodetic GNSS receivers that have been run in RTK (Real Time Kinematics) mode. The geomatic survey has been carried out by employing 3 station points and exploiting the classical triangulation scheme for local reference networks; conversely the use of GNSS receivers, employed for the survey of San Lorenzo Gate and a sett paved piece of Latina road, has allowed us to establish a global reference frame and hence data input in a GIS system. The use of the GIS software has allowed us to integrate and enrich the typology of the technical drawings associated with the site framing thanks to the superposition of several raster maps and to the input in the map of vectorial items geo-referenced on the basis of the surveyed coordinates.

Besides the photographic documentation taken as evidence of the excavations, accurate close-range photogrammetric measurements (D'Urso et alii, 2014) have allowed us to perform detailed measurements on some findings such as human remains and paving fragments as well as subsequent elaboration of 3D models.

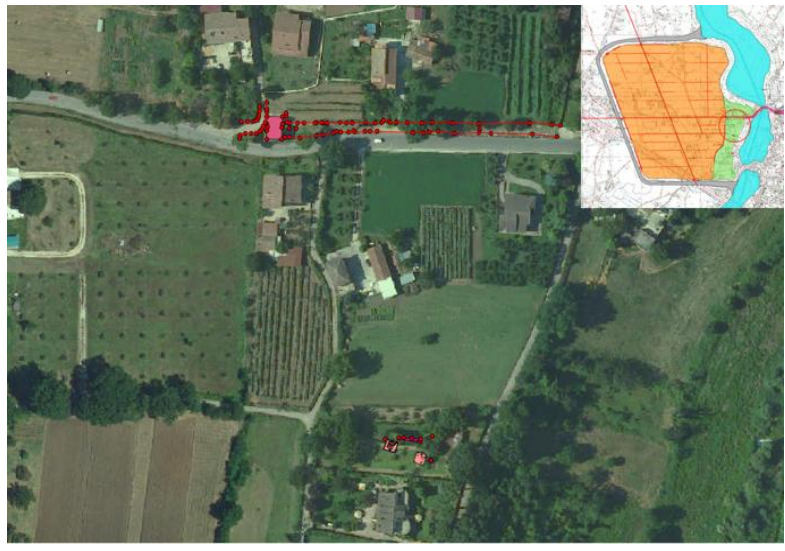

Figure 3. Area of GPS surveying and digs

\subsection{Description of the findings}

The following figures show the wireframe plans of the two digs and of the wall piece. the station points as well the detailed descriptions of all findings in their original positions, as also witnessed from the ortho-images.

In particular the Figure 5 illustrates the procedure adopted for the digital reconstruction of the planimetric profiles of each finding that has been obtained by superimposing the ortho-rectified images geo-referenced in a GIS framework; 
these last ones have been used to create wireframe plans for each dig and each stratigraphical unit.

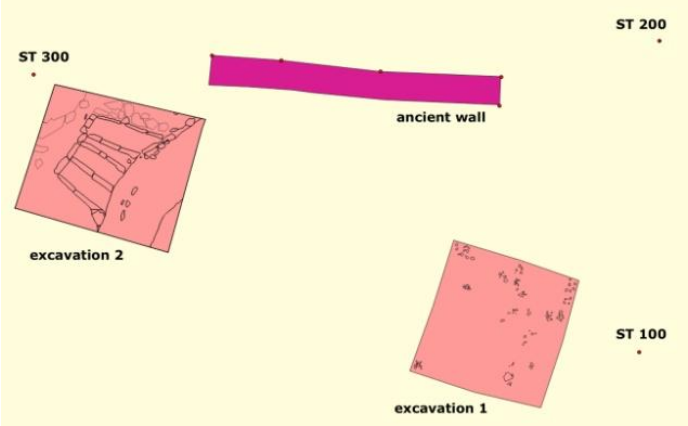

Figure 4. GIS snapshot with excavations plan

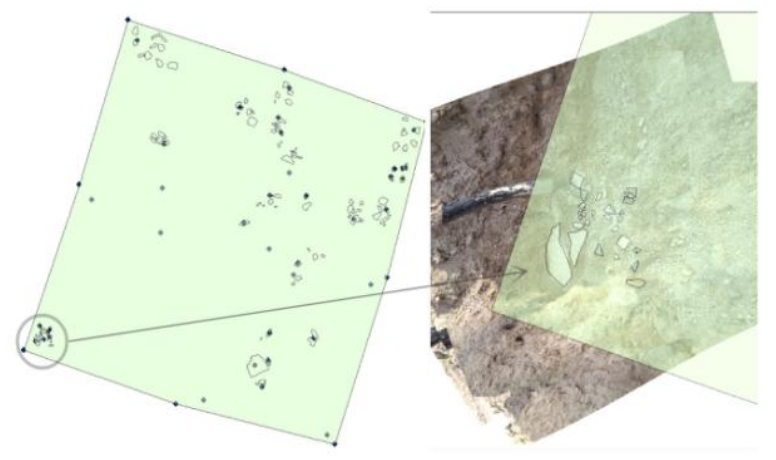

Figure 5. Plan and details of orthoimages of the first archaeological dig

In the first archaeological dig the vertical stratigraphical units have been significantly upset by the farm works carried out over years. For this reason it has been decided to identify stratigraphical units within which it has been possible to recover lithic ruins, ceramic fragments and remains of human bones. Thanks to unmodified stratigraphical units it has been possible to rescue fragments of pavements made for the Church in the XII century. In particular a portion of pavement has shown the presence of a first paving phase that can be dated to the beginning of the XII century on which, subsequently, it was placed a second pavement, of mosaic shape as well. In turn this last one can be attributed to the same artistic movements corresponding to four generations of marble craftsmen active in the city of Rome around the XII and XIII century and known as Cosmati; for this reason such pavements are denominated Cosmateschi.

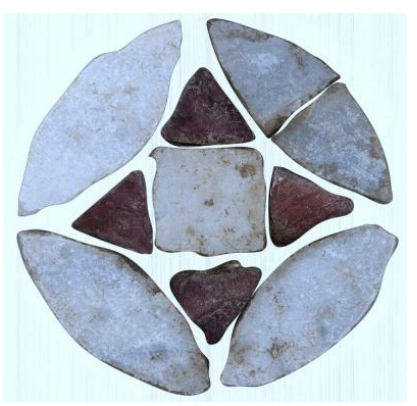

Figura 6. Photogrammetry close-range of a fragment of a Cosmatesco pavement
The photogrammetric restitution close-range of a fragment of this pavement shown in the Figure 6 has been obtained by processing three images, a nadiral one and two lateral shots obtained by a photogrammetric IMACON camera having a digital back and a frame size of $30 \mathrm{~cm}$. (D'Urso 2016; Germani et alii, 2017).
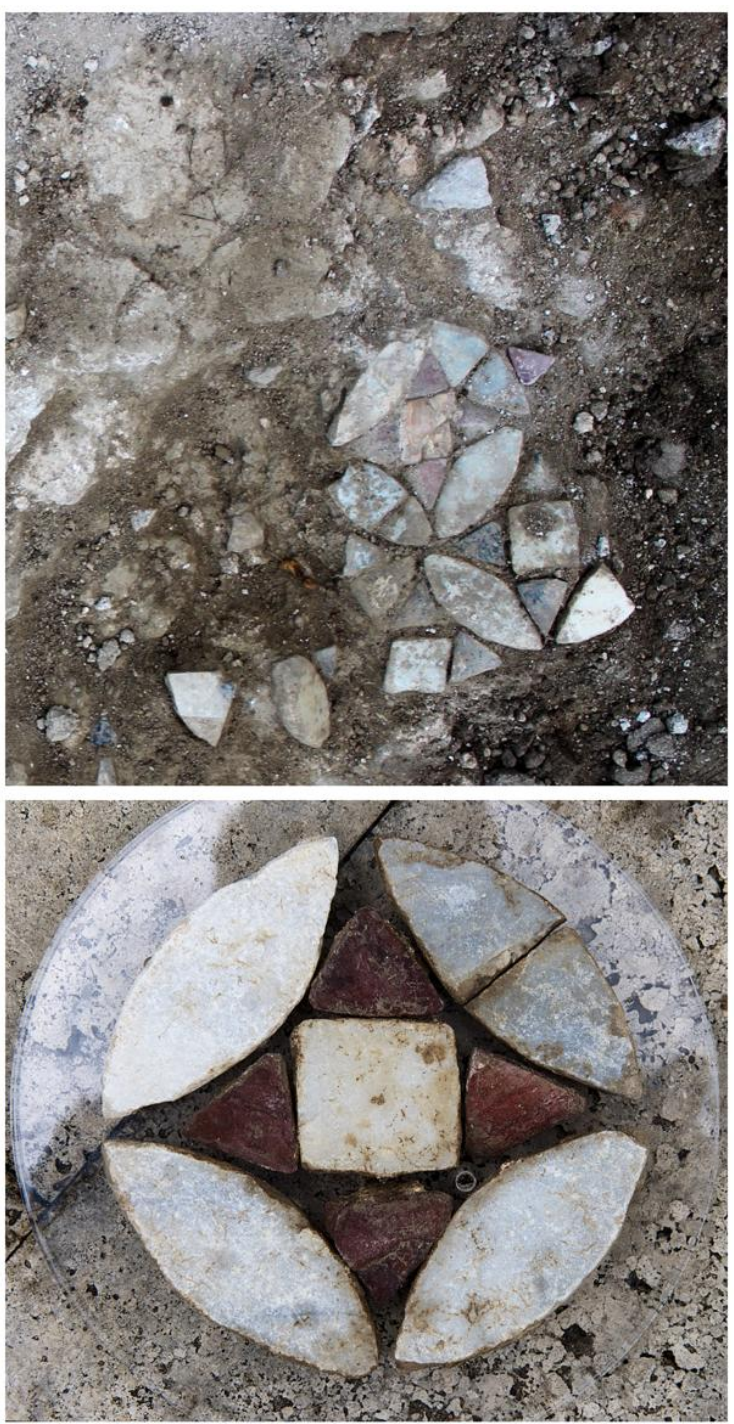

Figure 7. First dig in the S. Maria degli Angeli Church and in - situ reconstruction of an item of the decorative geometric pattern

In the second archaeological dig the excavation has allowed us to recover a portion of the perimetral walls of a building that is older than the ruins of the Church visible to the surface and, seemingly, completely disconnected from them. Such a structure appears to be made of a base row made of large square blocks on which it was erected a masonry made of stones, brick wastes and mortar. On this masonry wall four so - called a cista burials are grafted; two of them are characterized by single inhumations while the remaining two by twin inhumations. All of them present a casket made of lithic blocks. Although the cover blocks of the casket squared have been partially removed and/or destroyed, probably as a result of desecration and/or looting of different epochs, there have been found in the field around the coffins some coins, small rings and fragments of glassed ceramics that have 
provided useful information for dating the human remains, probably belonging to the medieval age.

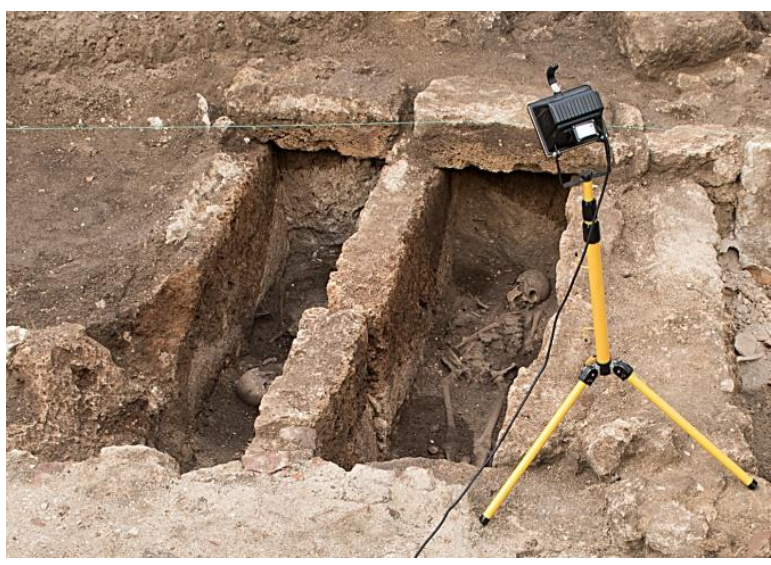

Figure 8. Archaeological digs of tumbs a cista

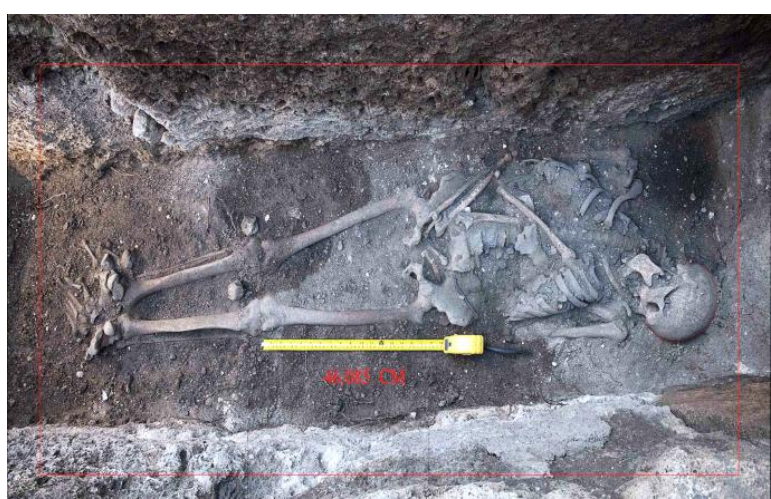

Figure 9. Human bones

\section{IMPLEMENTATION OF AN INTRA-SITE GIS}

The free software Quantum - GIS has been selected as reference software for implementing the GIS project. On the parallel side, as a comparison, some 3D elaborations have been carried out by using the commercial software ArcGIS. Both softwares allow for exporting projects in a format compatible with web platform. Proper survey tasks and effective protocols of computerized management by means of the intra-site GIS of the data associated with the case study have allowed us to set up a detailed and precise database (D'Andrea, 2003). One of the reasons for which such a procedure is progressively replacing traditional procedures of storage and cataloguing used by archaeologists on site is the in - situ preservation of the dataset memory, what is normally destroyed by the digs; conversely, visualization and consultation can provide useful elements for interpretation and setting the contest of findings. In a work protocol applicable to an excavation three successive steps can be identified: 1) Organization of a database for the georeferenced archaeological data; 2) 2D and 3D reconstruction of the collected data in model useful subsequent elaborations; 3) Development of applications for intra-site analysis (Katsianis M. , 2008; Tsipidis et alii, 2005).

$3 \mathrm{D}$ analysis represents the applicative framework of greater interest for what concerns the excavation context, mainly for the intrinsic capacity of keeping intact those archaeological information of topological and stratigraphical nature that alternative tools are not able to make in GIS framework. The
GIS implementation has followed a twofold logic: on one side the framing of the old topography of the site and of its time evolution by making use of a cartographic basis in a scale of 1:5000, that is the CTR of Lazio Region; on the other one the plotting of maps in detailed scales of all the surveyed elements during the excavation and of analysis of the area of interest by using as support for planimetric identification of the findings images suitably orthorectified and georeferenced in a GIS. Hence, once a reference frame has been chosen, vectorial elements associated with localization of the macro-areas of villages dating the roman, late antique and late medieval period of the old Aquinum, can be established so as to include the indication of the basic topographic elements (of urban and non-urban nature) for which it can be assessed an archaeological evidence of direct and/or indirect nature (old lakes, walls remains, monuments, ancient roads, old gates). They represent a reference to a comprehensive historical point of view and to contextualize the two excavation areas associated with the first and second digs can be represented by means of schematic and interactive layouts. It is possible to superimpose such a representation in a GIS framework with the orthophotos of the territory and with the Regional Technical Chart. For what concern the excavations, two interactive maps have been made, one for each stratigraphical unit, easily exported in .html format thanks to the QGis2web plugin. In each screen page of the informative system it is possible to interact in several ways with the map in order to understand both the position of the study area and descriptive elements of the findings, such as the identification number and the plano-altimetric coordinates of the surveyed points, the description of findings, the illustration of the images associated with the point or reference area, according to a concise representation of the elements belonging to the excavation dataset. In particular it is possible, by means of queries, to select information for each finding such as date, material and typology. On-line diffusion of the surveyed information, by means of on-line consultation, will be possible once the exported $\mathrm{html}$ file will be loaded on the server, a task that represents the next step of the proposed research program.

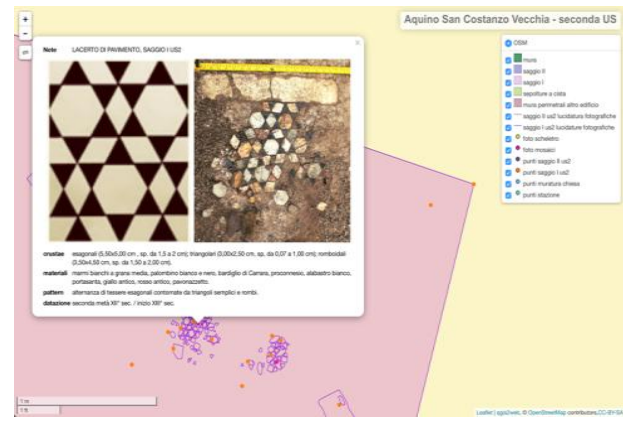

Figure 10. Export Web first dig, SU II

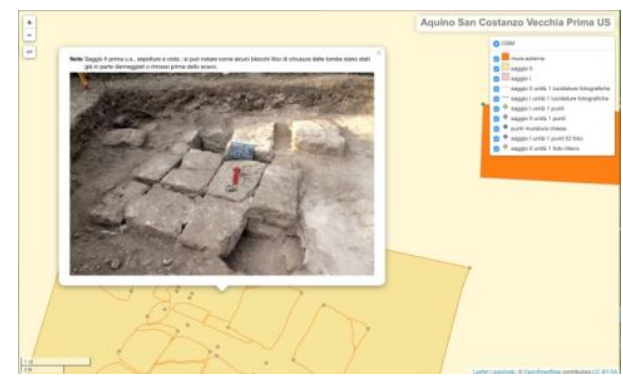

Figure 11. Export web, second dig, SU I 


\subsection{Elaboration of three-dimensional models}

The set up of 3D digital models represents the optimal methodology to preserve the excavation memory. The elaboration of the DSM in Figure 12 pertaining to the two stratigraphical units of the first dig has been carried out by starting from the coordinates of points surveyed, in the plan and along the border of excavation, by a total station. Visualization in fig. 12 of the two stratigraphical units of the first dig has been obtained by the ArcScene module.

Green and violet colors represent the extrusion of the findings associated, respectively, with the first and second stratigraphical unit; the points surveyed by a total station and the projection of the excavation border are shown as well. The Digital Surface Model has been obtained by making use of the ArcGIS software and following a step-by-step procedure based on the following items:

1) Fitting by linear interpolation of the mesh associated with the points surveyed with a total station;

2) Set up of a Triangular Irregular Network (TIN);

3) Generation of the Digital Surface Model (DSM);

4) Editing for 3D web visualization (ArcScene).

The tabular file with the (surveyed and interpolated) points has been subsequently imported, converted to a vectorial format and geo-referenced by means of a GIS software.

Set up of the TIN is easily accomplished by means of a tool of GIS software denominated Create TIN.

Subsequently, by means of a further tool named From TIN to raster, it is possible to convert the spatial information embedded in the TIN to a raster object, what represents the DSM for the case at hand.

Finally the DSM is edited for 3D visualization by means of a module of the ArcGIS software, named ArcScene; this allows one to modify some graphical and geometrical parameters of the object in $3 \mathrm{D}$ as well as to visualize several objects that mutually related in space.

Layers associated with surveyed points, photographic polishings and with the outlines of the significant outcomes of each stratigraphical unit have been edited so as to easily allow for a simple and intuitive identification of the findings in the excavation area.

Selection and reading of data associated with the survey are possible by direct navigation, by mouse clicking on the item to be questioned or by predefined queries that can be selected from the toolbar.

By following a similar procedure and using the same dataset of points it has been possible to make, in Q-GIS, a 3D model of the excavation area obtained as superposition of raster, namely the two DSM associated with the excavation, and vectorial objects. The model has been exported to the web by using a plugin of the Q-GIS software denominated Qgis2treejs.

Although it does not yield the some level of visualization allowed by the ESRI application ArcScene, such a free plugin is particularly useful since it is user-friendly and allows for an automatic export of the 3D model in the .html format thanks to an intuitive graphical front-end in which spatial coordinates of points and the fields of the controllable vectorial files can be visualized.

Moreover such an opportunity is absent in the ESRI software since this allows the user to export only in formats that are exclusively compatible with the proprietary web platforms.

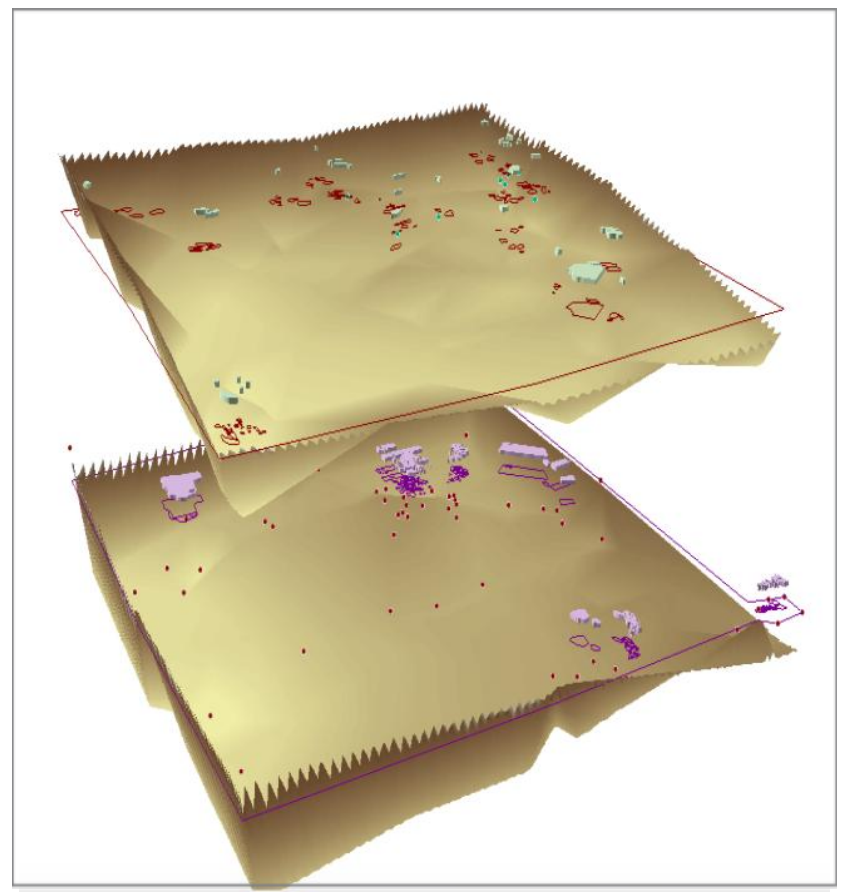

Figure 12. 3D visualization of stratigraphical units in the first dig

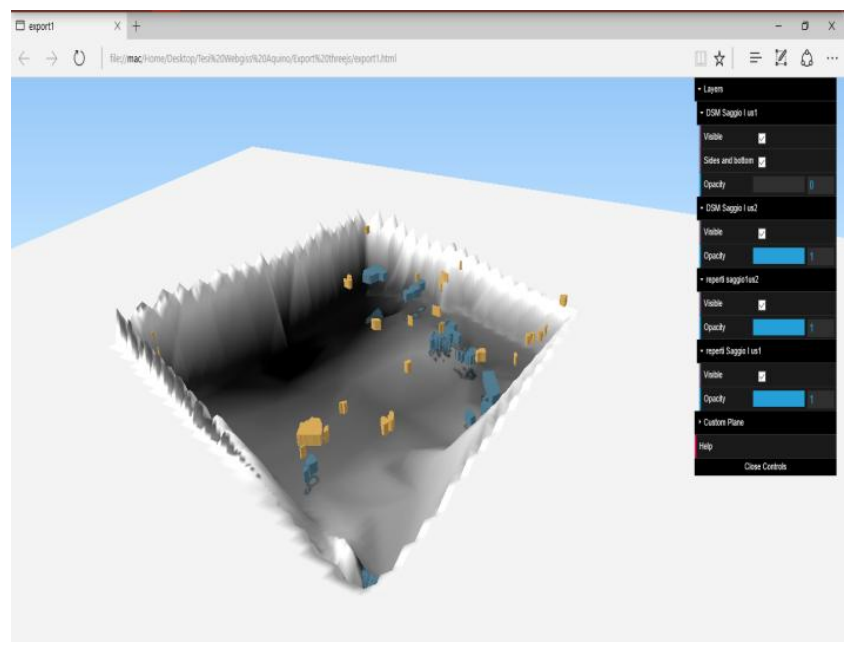

Figure 13. Web export of the 3D model pertaining to the two stratigraphical units of the first dig

Furthermore the geo-referenced 3D model of the San Lorenzo Gate shown in the Figure 14 has been obtained by processing with the image-based software Agisoft 310 images and has allowed for a detailed representation of the construction details and of its preservation state. 


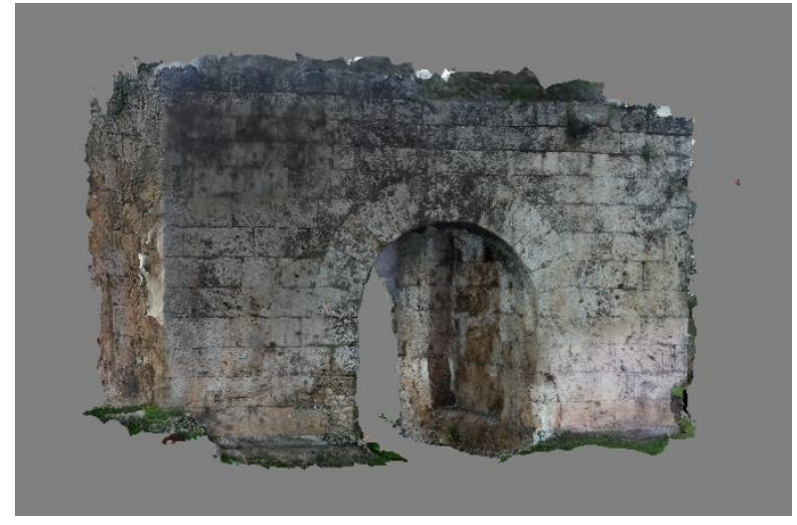

Figura 14. 3D model of the San Lorenzo Gate

Finally, with a view towards the subsequent cataloguing and musealization, particular attention has been paid to the human remains. A 3D model, inclusive of the orbital planes, of one of the discovered skulls has been rebuilt by the software Agisoft. This will allow us to carry out biometric measurements and comparative analysis that can be repeated digitally without the need of operating directly on the artifact, that by its own nature is characterized by a high perishability. Thus a proper geometric reconstruction and datation is made possible.

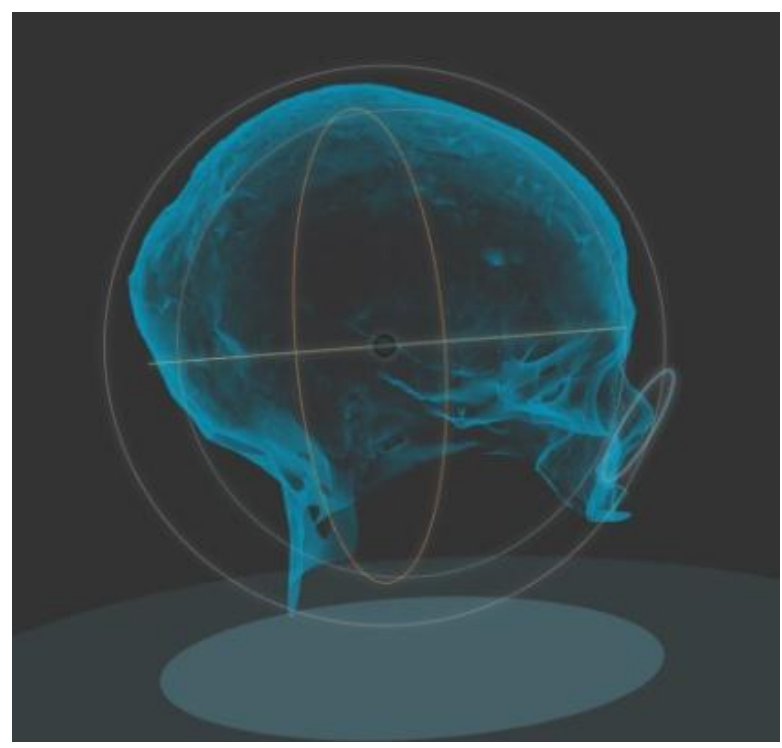

Figure 15. 3D model with orbital planes

\section{CONCLUSIVE REMARKS}

The implementation of an intra-site GIs here illustrated establishes as its objectives an improvement of the operative procedures, by extrapolating from this process useful considerations of more general nature that can be applied to analogous investigation contexts.

A dataset obtained with traditional topographic techniques, characterized by low costs and quick execution times, has allowed for the elaboration of geographical and archaeological data, mainly in $2 \mathrm{D}$ and $3 \mathrm{D}$ models, that properly synthesize and represent the excavation context by making its memory material.

To this end some basic issues concerning three aspects have been investigated: acquisition geometry of the spatial data; acquisition geometry of the images; cataloguing of the findings. Hence the definition of a standard protocol that can be applied to the excavation context, aimed to the set up of a purely digital workflow, similarly to what has been actually implemented and illustrated in the paper, represents a starting point for future campaigns of archaeological digs.

\section{REFERENCES}

Azevedo de, M. , C., 1949 Aquinum (Aquino): Regio 1, Latium et Campania, Roma, Istituto di Studi Romani Editore

Bellini, G. , Murro, G. , Trigona , S. L ., 2014 La Valle del Liris dalla colonizzazione all'alto medioevo(Aquinum, Interamna Lirenas, Minturnae). Viabilità ed insediamenti lungo una direttrice fluviale Alvarez, J. M. , Nogales, T. Rodà, I. , (eds.), Proceedings of XVIII International Congress of Classical Archaeology, vol. II

Bitelli, G. , Girelli, V. A. , Tini, M. A. , Vittuari, L. , 2004. Low-height aerial imagery and digital photogrammetrical processing for archaeological mapping International Archives of the Photogrammetry, Remote Sensing and Spatial Information Sciences, XXXV, Part B, pp. 498 - 503

Ceraudo, G., 2012. Progetto Ager Aquinas. Indagini aerotopografiche finalizzate allo studio della città romana di Aquinum (Lazio, Italia) E. Vermeulen, G. J. Burgers, Keavy S. , Corsi, C. (eds.), An offprint from Urban Landscape Survey in Italy and the Mediterranean. Oxbow Books, Oxford, UK

D’Andrea A., 2003. Analisi spaziali Intra - Site. Soluzioni GIS per lo scavo archeologico

Archeologia e Calcolatori 14, 329 - 335

D'Urso M.G. , Marino C., Rotondi A.. 2014 On 3D dimension: study cases for archaeological sites The International Archives of the Photogrammetry, Remote Sensing and Spatial Information Sciences, Volume XL-6, 2014, ISPRS Technical Commission VI Symposium, $19-21$ May 2014, Wuhan, China

D’Urso, M. G. , 2016 Acquisizioni geomatiche per un sito archeologico lungo la via Francigena: primi risultati. Ephemeris Dacoromana Atti dell'Accademia di Romania di Roma, XVII, 2015, Roma 2016 (ISSN 1582-1854), pp: 139. 142

Germani, M. , 2016 Prima campagna di scavo del complesso di S. Costanzo Vecchia sito in contrada S. Pietro Vetere ad Aquinum: osservazioni preliminari

Ephemeris Dacoromana, XVIII, pp. 171 - 179

Germani M., Canetri E., D'Urso M.G., Cascavilla R., Florissi V., Riccardi L. 2015 LACERTI DI MOSAICI COSAMTESCHI DALLA CATTEDRALE DI S. COSTANZO VECCHIA PRESSO AQUINO (FR):NUOVI DATI DALLA CAMPAGNA DI SCAVI AISCOM Atti del XXII Colloquio dell'Associazione Italiana per lo Studio e la Conservazione del Mosaico Edizioni Scripta Manent, Via Empolitana, 326 - 00019 TIVOLI (Roma) 2017 ISBN 978-88909657-7- 
Katsianis, M., Tsipidis, S. , Kotsakis, K. , Kousoulakou, A. , 2008 A 3D digital workflow for archaeological intra - site research using GIS Journal of Archaeological Science 35, $655-667$

Nicosia, A. , 1990 I longobardi nel Lazio meridionale (sec. $\mathrm{VI}^{\circ}$ ) Scritti in memoria di G. Marchetti Longhi vol.I Biblioteca di Latium, 10, Anagni, Istituto di Storia $e$ dell'Arte del Lazio Meridionale

Nicosia, A. , Ceraudo, G. (a cura di), 2007 Spigolature aquinati: studi storico - archeologici su Aquino e il suo territorio Atti della giornata di studio - Aquino, Museo della Città, 19 maggio 2007, Castrocielo, casa ed. Philia

Pescarin, S., 2006 Open Source in archeologia. Nuove prospettive per la ricerca

Archeologia e Calcolatori 17, 137 - 155

Pietrobono, S., 2008 Nuovi dati per lo studio della cattedrale di Aquinum in età paleocristiana e altomedievale

Atti del XV Congreso Internacional de Arqueología Cristiana (XV CIAC). Toledo (Spagna) 8-12 settembre 2008 Roma Città del Vaticano, 2013, 1179-1194

Piro, S. , Ceraudo , G. , Zamuner , D. , 2011 Integrated Geophysical and Archaeological Investigations of Aquinum in Frosinone, Italy Archaeological Prospection 18, 127 - 138.

Tsipidis, S., Koussoulakou A. , Kotsakis, K. , 2005 3D GIS visualization of archaeological excavation data Proceedings of 22th International Cartographic Conference, La Coruna, Spain (ICC 2005) 